\title{
NCCN Guidelines as a Model of Extended Criteria for Lung Cancer Screening
}

\author{
Brady J. McKee, MD; Shawn Regis, PhD; Andrea K. Borondy-Kitts, MS, MPH; Jeffrey A. Hashim, MD;
} Robert J. French Jr, MD; Christoph Wald, MD, MBA, PhD; and Andrea B. McKee, MD

\section{Abstract}

Background: This review assessed the performance of patients in NCCN high-risk group 2 in a clinical CT lung screening (CTLS) program. Methods: We retrospectively reviewed screening results for all patients from our institution undergoing clinical CTLS from January 2012 through December 2016, with follow-up through June 2017. To qualify for screening, patients had to meet the NCCN Guidelines high-risk criteria for CTLS, have a physician order for screening, be asymptomatic, be lung cancer-free for 5 years, and have no known metastatic disease. We compared demographics and screening performance of NCCN high-risk groups 1 and 2 across $>4$ rounds of screening. Screening metrics assessed included rates of positive and suspicious examinations, significant incidental and infectious/inflammatory findings, false negatives, and cancer detection. We also compared cancer stage and histology detected in each NCCN high-risk group. Results: A total of 2,927 individuals underwent baseline screening, of which $698(24 \%)$ were in NCCN group 2. On average, group 2 patients were younger ( 60.6 vs 63.1 years), smoked less (38.8 vs 50.8 pack-years), had quit longer (18.1 vs 6.3 years), and were more often former smokers (61.4\% vs $44.2 \%$ ). Positive and suspicious examination rates, false negatives, and rates of infectious/inflammatory findings were equivalent in groups 1 and 2 across all rounds of screening. An increased rate of cancer detection was observed in group 2 during the second annual (T2) screening round $(2.7 \%$ vs $0.5 \% ; P=.005)$, with no difference in the other screening rounds: baseline (T0; $2 \%$ vs $2.3 \% ; P=.61)$, first annual (T1; $1.2 \%$ vs $1.7 \% ; P=.41)$, and third annual and beyond $(\geq \mathrm{T} 3 ; 1.2 \%$ vs $1.1 \% ; P=1.00)$. Conclusions: CTLS appears to be equally effective in both NCCN high-risk groups.

J Natl Compr Canc Netw 2018;16(4):444-449 doi: 10.6004/jnccn.2018.7021

\section{Background}

NCCN, the Centers for Medicare \& Medicaid Services (CMS), and the US Preventive Services Task Force (USPSTF) recommend annual CT lung screening (CTLS) for current and former heavy smokers meeting the National Lung Screening Trial (NLST) entry criteria. ${ }^{1-4}$ All 3 organizations have expanded their screening recommendations to include older patients, younger patients, and/or patients with additional risk factors for lung cancer. Inclusion of these additional populations has generated controversy given the lack of formal evaluation in the NLST. ${ }^{5}$ The NCCN Clinical Practice Guidelines in Oncology (NCCN Guidelines) for Lung Cancer Screening, v1.2012, recommended annual CTLS for 2 groups of high-risk individuals ${ }^{1}$ :

From Lahey Hospital \& Medical Center, Burlington, Massachusetts. Submitted November 14, 2017; accepted for publication February 28, 2018. The authors have disclosed that they have no financial interests,
- Group 1: Current smokers or former smokers who have quit within 15 years aged 55 to 74 years with a $\geq 30$ pack-year smoking history (NLST population; NCCN category 1 recommendation).

- Group 2: Current and former smokers aged $\geq 50$ years with $a \geq 20$ pack-year smoking history and at least one of the following additional lung cancer risk factors, not including secondhand smoke exposure (NCCN category 2B recommendation in v1.2012 ${ }^{1}$; currently a category $2 \mathrm{~A}$ recommendation in v3.2018 $)$ :

- Personal history of smoking-related cancer

- History of lung cancer in a first-degree relative

- Occupational exposure to known lung carcinogens

arrangements, affiliations, or commercial interests with the manufacturers of any products discussed in this article or their competitors.

Correspondence: Brady J. McKee, MD, Lahey Hospital \& Medical Center, 41 Mall Road, Burlington, MA 01805. Email: Brady.McKee@lahey.org 
- Residential radon exposure (documented sustained and substantial)

- Chronic lung disease, including emphysema and pulmonary fibrosis

Individuals in both NCCN group 1 and 2 should be potential candidates for definitive therapy and free of signs and symptoms of lung cancer.

In January 2012, in response to the NLST publication and the release of the NCCN Guidelines for Lung Cancer, our institution began offering clinical CTLS as a community benefit to all individuals meeting either NCCN group 1 or group 2 high-risk criteria. A comprehensive explanation of the design and implementation of our CTLS program, including recruitment, enrollment, and follow-up of participating individuals at high risk, was previously published. ${ }^{7}$ The present study compares demographic characteristics and screening metrics, including rates of positive findings, significant incidental findings, and malignancy, between our group 1 and 2 populations.

\section{Methods}

This retrospective single-center study was approved by the Lahey Hospital \& Medical Center (LHMC) Institutional Review Board. We report results of consecutive individuals from LHMC who underwent clinical CTLS from January 1, 2012, through December 31, 2016. To qualify for screening, all individuals had to be at high risk for lung cancer according to the NCCN Guidelines, v1.2012; be asymptomatic; have a physician order for CTLS; be free of lung cancer for at least 5 years; and have no known metastatic disease. Continuing medical education events and decision support tools detailing the screening process and the NCCN group 1 and 2 high-risk criteria were made available to help ordering physicians conduct the CTLS shared decision-making visit. ${ }^{7}$ All CTLS examinations were performed on $\geq 64$ row multidetector CT scanners at $100 \mathrm{kV}$ and 30 to 100 $\mathrm{mA}$ depending on availability of iterative reconstruction software. Image interpretation was performed by radiologists credentialed in CTLS reporting using LungRADS, version 1.0 (LR). ${ }^{7,8}$ Examinations were classified as "negative" (LR 0, 1, and 2), "positive" (LR 3, LR 4A/B/X), or "suspicious" (LR 4A/B/X) based on LR criteria. Computer-aided detection software was not used. Group 1 and 2 screening results were analyzed based on round of screening, with TO representing the baseline (prevalence) examination and $\mathrm{T} 1, \mathrm{~T} 2$, and $\geq \mathrm{T} 3$, reflecting first, second, and $\geq$ third annual incidence screening examinations. The next round of screening was defined as the examination following a negative result or the examination following the first negative examination after a positive result. Interval examinations performed to follow-up after a positive result were not included in this analysis.

Variables assessed included cancer detection rate (CDR), positive predictive value (PPV), suspicious predictive value (SPV), rate of infectious/inflammatory findings, rate of significant incidental findings, and false-negative rate. PPV and SPV were defined as the probability of a cancer diagnosis after either a positive or suspicious screening result, respectively, without an intervening negative examination in both cases. We defined a significant incidental finding as any unexpected new and/or unknown findings requiring clinical or imaging evaluation before the next CTLS examination. Given the high prevalence of coronary artery calcifications and emphysema in the CTLS population, these findings were not classified as significant incidentals (Table 1). Cancer diagnosis within 12 months of a negative examination resulted in classification of those results as a false-negative. All patients were followed for a minimum of 6 months, with follow-up ending on June 30, 2017, or until the date of the next annual screening round after December 31, 2016, whichever occurred first. P values for numerical/ continuous variables were calculated using ANOVA. $P$ values for categorical variables were determined using the chi-square test except in cases with $<5$ events, for which Fisher exact test was used. For all statistical analyses, the significance level for differences was set at $P \leq .05$. All statistical analysis was performed using SPSS Statistics, version 21 (SPSS Inc.).

\section{Results}

Between January 1, 2012, and December 31, 2016, 3,449 qualified individuals from our institution were referred for CTLS; 814 (23.6\%) did not meet group 1 criteria but did fulfill group 2 criteria (Figures 1 and 2). The most common reasons for not meeting group 1 criteria were aged $<55$ years $(30.8 \%)$ and $\geq 15$ quit-years $(31.7 \%)$ (Figure 1$)$. For individuals meeting group 2 criteria, the most common qualifying additional risk factors were chronic lung disease $(32.4 \%)$ and a first-degree relative with lung cancer $(31.7 \%)$ 
McKee et al

\begin{tabular}{|c|c|c|c|c|c|c|c|c|}
\hline \multirow[b]{2}{*}{ Qualitative Radiology Assessment } & \multicolumn{4}{|c|}{ CACs } & \multicolumn{4}{|c|}{ Emphysema } \\
\hline & Overall & Group 1 & Group 2 & $P$ Value & Overall & Group 1 & Group 2 & $P$ Value \\
\hline None & $23.9 \%$ & $21.8 \%$ & $29.4 \%$ & .004 & $43.3 \%$ & $39.7 \%$ & $53.1 \%$ & $<.001$ \\
\hline Mild & $28.9 \%$ & $27.9 \%$ & $31.7 \%$ & .17 & $38.6 \%$ & $39.4 \%$ & $36.4 \%$ & .3 \\
\hline Moderate & $25.4 \%$ & $27.2 \%$ & $20.6 \%$ & .01 & $14.3 \%$ & $16.6 \%$ & $8.1 \%$ & $<.001$ \\
\hline \multirow[t]{2}{*}{ Marked } & $21.9 \%$ & $23.2 \%$ & $18.3 \%$ & .06 & $3.8 \%$ & $4.3 \%$ & $2.5 \%$ & .1 \\
\hline & \multicolumn{2}{|l|}{ Overall } & \multicolumn{2}{|c|}{ Group 1} & \multicolumn{2}{|c|}{ Group 2} & \multicolumn{2}{|c|}{$P$ Value } \\
\hline At least mild CAC and/or emphysema & \multicolumn{2}{|l|}{$88.3 \%$} & \multicolumn{2}{|c|}{$90.1 \%$} & \multicolumn{2}{|c|}{$83.6 \%$} & \multicolumn{2}{|c|}{.001} \\
\hline Marked CAC and/or marked emphysema & \multicolumn{2}{|l|}{$24.7 \%$} & \multicolumn{2}{|c|}{$26.3 \%$} & \multicolumn{2}{|c|}{$20.3 \%$} & \multicolumn{2}{|c|}{.02} \\
\hline
\end{tabular}

Abbreviations: CAC, coronary artery calcifications; CTLS, CT lung screening.

(Figure 2). A history of chronic lung disease (either emphysema or pulmonary fibrosis) was present in half of the $12.9 \%$ of group 2 individuals with multiple qualifying risk factors.

A total of 2,927 patients $(84.9 \%)$ underwent a baseline CTLS examination, with 698 of these (23.8\%) in group 2. On average, patients in group 2 were slightly younger (60.6 vs 63.1 years; $P<.001)$, smoked less $(38.8$ vs 50.8 pack-years; $P<.001)$, quit for longer periods (18.1 vs 6.3 years; $P<.001$ ), were less likely to be current smokers $(38.6 \%$ vs $55.8 \%$; $P$ <.001), and were less likely to have radiographically evident emphysema and/or coronary artery calcifications ( $83.6 \%$ vs $90.1 \% ; P=.001$ ) than group 1 (Tables 1 and 2). A total of 1,772, 1,094, and 689 patients underwent T1, T2, and $\geq \mathrm{T} 3$ annual incidence scans, respectively, with approximately $24 \%$ in group 2 at each incidence round (Table 3). Overall, 6,482 screening examinations were performed across all rounds of screening, with 1,555 (24.0\%) in group 2 . The average duration of follow-up was 30.4 months (group 1, 30.2 months; group 2, 31.3 months; $P=.4$ ) (Table 4).

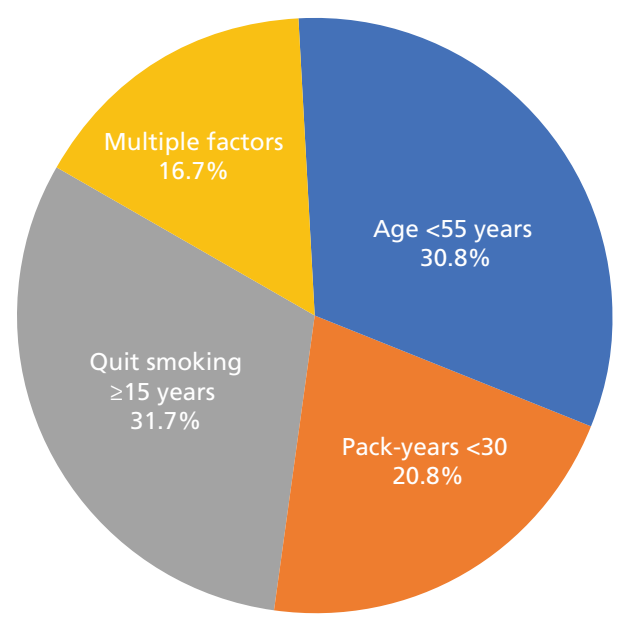

Figure 1. Common reasons group 2 were ineligible for group 1.
Overall positive rates were $12.7 \%, 6.7 \%, 5.9 \%$, and $6.0 \%$ at $\mathrm{T} 0, \mathrm{~T} 1, \mathrm{~T} 2$, and $\geq \mathrm{T} 3$ screening rounds, respectively, with no significant difference between group 1 and 2 (Table 3). There was also no significant difference in rates of suspicious examinations, false negatives, or infectious/inflammatory findings at each round of screening (Tables 3 and 5). An excess of significant incidental findings in group 1 was found in the T1 round of screening ( $3.0 \%$ vs $1.2 \% ; P=.03)$, with no significant difference in other screening rounds (Table 5).

A total of 113 lung cancers were diagnosed during the study interval, with $28(24.8 \%)$ in group 2 (Tables 4 and 6). Overall CDRs were 2.3\%, 1.6\%, 1.0\%, and $1.2 \%$ in the $\mathrm{T} 0, \mathrm{~T} 1, \mathrm{~T} 2$, and $\geq \mathrm{T} 3$ rounds, respectively, yielding PPVs between 15\% and 22\% and SPVs between $29 \%$ and $44 \%$. Although there were significantly increased CDRs in group 2 in the T2 round $(2.7 \%$ vs $0.5 \%$ for group $1 ; P=.005)$, there was no difference between groups for these metrics in the other screening rounds or overall ( $1.8 \%$ vs $1.7 \% ; P=.84)$. Group 2 patients tended to have early-stage disease $(92.6 \%$ vs

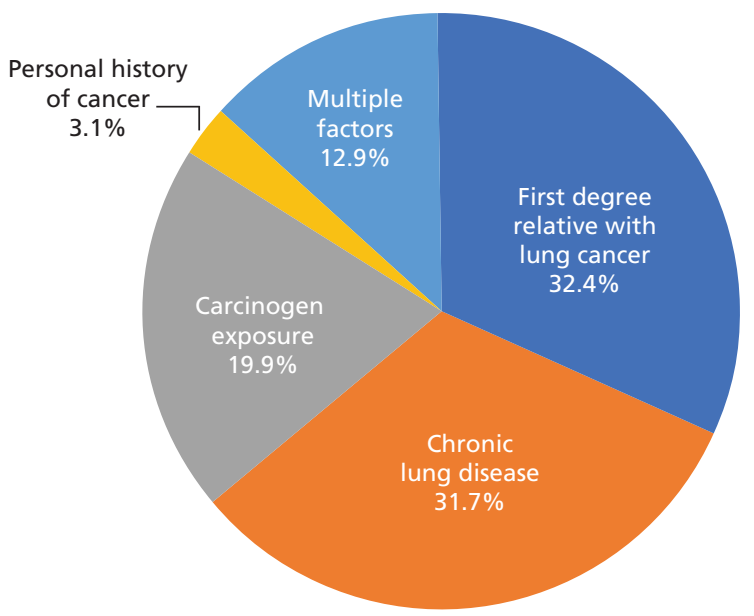

Figure 2. Qualifying risk factors for group 2. 
Extending Lung Cancer Screening Criteria

\begin{tabular}{|lcccc|}
\hline \multicolumn{5}{|l|}{ Table 2. Patient Demographics ${ }^{\mathrm{a}}$} \\
$\begin{array}{l}\text { Patient } \\
\text { Characteristics }\end{array}$ & Total & Group 1 & Group 2 & P Value \\
\hline Qualified & 3,449 & 2,635 & 814 & $\mathrm{~N} / \mathrm{A}$ \\
\hline Screened & 2,927 & $2,229(76.1 \%)$ & $698(23.8 \%)$ & $\mathrm{N} / \mathrm{A}$ \\
\hline Average age, y & 62.5 & 63.1 & 60.6 & $<.001$ \\
\hline Male & $55.6 \%$ & $55.7 \%$ & $55.2 \%$ & .8 \\
\hline $\begin{array}{l}\text { Average pack-year } \\
\text { smoking history }\end{array}$ & 47.9 & 50.8 & 38.8 & $<.001$ \\
\hline $\begin{array}{l}\text { Current smokers } \\
\begin{array}{l}\text { Average quit years } \\
\text { (former smokers) }\end{array}\end{array}$ & $51.7 \%$ & $55.8 \%$ & $38.6 \%$ & $<.001$ \\
\hline Average follow-up, mo & 30.4 & 6.3 & 18.1 & $<.001$ \\
\hline
\end{tabular}

Abbreviation: N/A, not applicable.

${ }^{a}$ Based on screened population.

$80.3 \% ; P=.66)$, adenocarcinoma histology $(67.9 \%$ vs $49.4 \% ; P=.37)$, and no evidence of disease $(78.6 \%$ vs 57.6\%; $P=.36$ ); however, these 3 differences did not reach statistical significance (see supplemental eTables 1-3, available with this article at JNCCN.org).

\section{Discussion}

Although smoking and age are the leading risk factors for development of lung cancer, other modifiable and hereditary risk factors may place individuals at equivalent or higher risk than the NLST population (group 1). ${ }^{1,9-12}$ In an effort to maximize the lifesaving potential of CTLS, several organizations, including CMS, USPSTF, the American Association for Thoracic Surgery, and NCCN, have selectively expanded their screening recommendations to include high-risk individuals who do meet the NLST criteria despite the limited research and empirical evidence for screening efficacy in these groups. ${ }^{1-3,9}$ The NCCN Guidelines for Lung Cancer Screening have been periodically reviewed and revised since their inception in October 2011 to account for new evidence and changes in accepted approaches to treatment. The most recent version (v3.2018) ex- pands the original qualifying group 2 additional risk factors to include any combination of factors (excluding secondhand smoke exposure), which increases the risk of lung cancer diagnosis within 6 years to $\geq 1.3 \%$ for all current and former smokers aged $\geq 50$ years with a $\geq 20$ pack-year smoking history. ${ }^{6}$

In our single-center 5-year experience screening NCCN group 1 and 2 high-risk individuals, we found that nearly all CTLS metrics for both NCCN groups across $\geq 4$ rounds of screening were similar, including rate of positive examination results, significant incidental findings, cancer detection, and false negatives, despite significantly lower smoking-related risk factors in the group 2 population at program entry (lower age, fewer pack-years, longer smoking cessation duration, and higher quit rates). These findings suggest that the addition of at least one of the NCCN-specified risk factors may compensate for any incremental decreased risk resulting from the lower age and smoking exposure in group 2 at program entry.

Many other CTLS program metrics were also similar between groups 1 and 2, including the likelihood of undergoing baseline screening following a qualified referral $(84.9 \%)$. In addition, there was a stable percentage of patients in group $2(24 \%)$ participating in each subsequent round of screening. Even the rate of infectious and inflammatory findings in these groups across all screening rounds $(\approx 7 \%)$ was the same. These similarities likely reflect the uniform process of our CTLS program staff, particularly regarding scheduling, pretest disclosure of the need to be asymptomatic, and posttest result notification and follow-up. ${ }^{13}$

As expected, the CDR in our program was highest at baseline screening $(2.3 \%$ and $2.0 \%$ in groups 1 and 2, respectively; $P=.61)$. Interestingly, the overall CDR remained $>1 \%$ for all incidence rounds of screening, including the fourth and later rounds, which were not assessed by the NLST (TO, T1, and $\mathrm{T} 2$ rounds only). ${ }^{4}$ Although there was a significant-

Table 3. CLTS Metrics by Screening Round: Examination Results

\begin{tabular}{|c|c|c|c|c|c|c|c|c|c|c|c|c|c|c|c|c|c|c|c|c|c|c|c|c|c|c|}
\hline \multirow{3}{*}{$\begin{array}{l}\text { Screening } \\
\text { Round }\end{array}$} & \multicolumn{5}{|c|}{ Total Scans } & \multicolumn{7}{|c|}{ Negative Scans } & \multicolumn{7}{|c|}{ Positive Scans } & \multicolumn{7}{|c|}{ Suspicious Scans } \\
\hline & \multirow{2}{*}{$\begin{array}{c}\text { Overall } \\
2,927\end{array}$} & \multicolumn{2}{|c|}{ Group 1} & \multicolumn{2}{|c|}{ Group 2} & \multicolumn{2}{|c|}{ Overall } & \multicolumn{2}{|c|}{ Group 1} & \multicolumn{2}{|c|}{ Group 2} & \multirow{2}{*}{$\frac{P \text { Value }}{.12}$} & \multicolumn{2}{|c|}{ Overall } & \multicolumn{2}{|c|}{ Group 1} & \multicolumn{2}{|c|}{ Group 2} & \multirow{2}{*}{$\frac{P \text { Value }}{.12}$} & \multicolumn{2}{|c|}{ Overall } & \multicolumn{2}{|c|}{ Group 1} & \multicolumn{2}{|c|}{ Group 2} & \multirow{2}{*}{$\begin{array}{c}P \text { Value } \\
.12\end{array}$} \\
\hline & & 2,229 & $76.2 \%$ & 698 & $23.8 \%$ & 2,554 & $87.3 \%$ & 1,933 & $86.7 \%$ & 621 & $89.0 \%$ & & 373 & $12.7 \%$ & 296 & $13.3 \%$ & 77 & $11.0 \%$ & & 146 & $5.0 \%$ & 119 & $5.3 \%$ & 27 & $3.9 \%$ & \\
\hline $\mathrm{T} 1$ & 1,772 & 1,338 & $75.5 \%$ & 434 & $24.5 \%$ & 1,653 & $93.3 \%$ & 1,249 & $93.3 \%$ & 404 & $93.1 \%$ & .85 & 119 & $6.7 \%$ & 89 & $6.7 \%$ & 30 & $6.9 \%$ & .85 & 57 & $3.2 \%$ & 43 & $3.2 \%$ & 14 & $3.2 \%$ & .99 \\
\hline $\mathrm{T} 2$ & 1,094 & 833 & $76.1 \%$ & 261 & $23.9 \%$ & 1,029 & $94.1 \%$ & 784 & $94.1 \%$ & 245 & $93.9 \%$ & .88 & 65 & $5.9 \%$ & 49 & $5.9 \%$ & 16 & $6.1 \%$ & .88 & 34 & $3.1 \%$ & 23 & $2.8 \%$ & 11 & $4.2 \%$ & .24 \\
\hline$\geq \mathrm{T} 3$ & 689 & 527 & $76.5 \%$ & 162 & $23.5 \%$ & 648 & $94.0 \%$ & 496 & $94.1 \%$ & 152 & $93.8 \%$ & .89 & 41 & $6.0 \%$ & 31 & $5.9 \%$ & 10 & $6.2 \%$ & .89 & 25 & $3.6 \%$ & 19 & $3.6 \%$ & 6 & $3.7 \%$ & .95 \\
\hline Total & 6,482 & 4,927 & $76.0 \%$ & 1,555 & $24.0 \%$ & 5,884 & $90.8 \%$ & 4,462 & $90.6 \%$ & 1,422 & $91.4 \%$ & .29 & 598 & $9.2 \%$ & 465 & $9.4 \%$ & 133 & $8.6 \%$ & .29 & 262 & $4.0 \%$ & 204 & $4.1 \%$ & 58 & $3.7 \%$ & .47 \\
\hline
\end{tabular}

Abbreviation: CTLS, CT lung screening. 
McKee et al

\begin{tabular}{|c|c|c|c|c|}
\hline Variable & Total & Group 1 & Group 2 & $P$ Value \\
\hline Overall malignancy rate & $\begin{array}{c}113 / 2,927 \\
(3.9 \%)\end{array}$ & $\begin{array}{c}85 / 2,229 \\
(3.8 \%)\end{array}$ & $\begin{array}{l}28 / 698 \\
(4.0 \%)\end{array}$ & .8 \\
\hline Average follow-up, mo & 30.4 & 30.2 & 31.3 & .4 \\
\hline $\begin{array}{l}\text { Annualized malignancy } \\
\text { rate }\end{array}$ & $1.52 \%$ & $1.51 \%$ & $1.54 \%$ & 1 \\
\hline
\end{tabular}

ly increased CDR for group 2 in the T2 round $(2.7 \%$ vs $0.5 \% ; P=.005)$, overall annualized CDRs were the same for both groups (1.7\% vs $1.8 \%$ for groups 1 and 2 , respectively; $P=.84)$. The continued high $\mathrm{CDR}$ at incidence screenings would appear to support the recommendations by CMS, USPSTF, and NCCN for patients at high-risk for lung cancer to undergo annual rather than biannual screening for the duration of screening eligibility. ${ }^{1-3}$ Further, these rates suggest an improved cost-effectiveness of lung screening relative to the NLST, in which CDRs were $1.03 \%, 0.69 \%$, and $0.87 \%$ at T0, T1, and T2 rounds, respectively., 414

Our group 2 patients were more likely to be diagnosed with early-stage $(\leq \mathrm{II})$ non-small cell lung cancer $(92.6 \%$ vs $80.3 \% ; P=.66)$ and adenocarcinoma histology $(67.9 \%$ vs $49.4 \% ; P=.37)$; however, these trends did not reach statistical significance possibly due to small sample size. Differences in stage and histology may relate to differences in smoking-related risk factors and would appear to in part explain the higher rate of no evidence of disease after treatment observed in group 2, although this trend also did not reach statistical significance $(78.6 \%$ vs $57.6 \% ; P=.36$ ).

For every 3 patients in group 1 in our CTLS program, we enrolled 1 patient in group 2 . Given the estimated size of group 1 at 7 million Americans, this suggests that there could be as many as 2 million Americans in group 2 at high-risk for lung cancer who do not meet either CMS or USPSTF eligibility criteria. ${ }^{1,2,4}$ If our results are reproducible across the variety of institutions performing CTLS nationwide, expanding CMS and USPSTF eligibility to include patients in group 2 has the potential to save thousands of additional lives every year. ${ }^{15}$

\section{Conclusions}

We provide empirical evidence of screening efficacy in the NCCN group 2 population at a single institution. Although there were significant differences in smoking history and age at program entry, nearly all screening metrics for both NCCN group 1 and 2 were similar across $\geq 4$ rounds of screening. Multiinstitutional investigation of group 2 is warranted to confirm similar results are broadly achievable.

CTLS appears to be equally effective in NCCN group 1 and 2 high-risk populations. Expanding national CTLS eligibility to include the NCCN group 2 population offers the potential to save thousands of additional lives each year.

\begin{tabular}{|c|c|c|c|c|c|c|c|c|c|c|c|c|c|c|c|c|c|c|c|c|c|}
\hline \multirow{3}{*}{$\begin{array}{l}\text { Screening } \\
\text { Round }\end{array}$} & \multicolumn{7}{|c|}{ False Negatives } & \multicolumn{7}{|c|}{ Significant Incidental Findings } & \multicolumn{7}{|c|}{ Infectious/Inflammatory Findings } \\
\hline & \multicolumn{2}{|c|}{ Overall } & \multicolumn{2}{|c|}{ Group 1} & \multicolumn{2}{|c|}{ Group 2} & \multirow{2}{*}{$\frac{P \text { Value }}{.14}$} & \multicolumn{2}{|c|}{ Overall } & \multicolumn{2}{|c|}{ Group 1} & \multicolumn{2}{|c|}{ Group 2} & \multirow{2}{*}{$\frac{P \text { Value }}{.23}$} & \multicolumn{2}{|c|}{ Overall } & \multicolumn{2}{|c|}{ Group 1} & \multicolumn{2}{|c|}{ Group 2} & \multirow{2}{*}{$\frac{P \text { Value }}{.59}$} \\
\hline & 3 & $0.1 \%$ & 1 & $0 \%$ & 2 & $0.3 \%$ & & 188 & $6.4 \%$ & 150 & $6.7 \%$ & 38 & $5.4 \%$ & & 219 & $7.5 \%$ & 170 & $7.6 \%$ & 49 & $7.0 \%$ & \\
\hline $\mathrm{T} 1$ & 2 & $0.1 \%$ & 2 & $0.1 \%$ & 0 & $0 \%$ & 1 & 45 & $2.5 \%$ & 40 & $3.0 \%$ & 5 & $1.2 \%$ & .03 & 120 & $6.8 \%$ & 92 & $6.9 \%$ & 28 & $6.5 \%$ & .76 \\
\hline $\mathrm{T} 2$ & 1 & $0.1 \%$ & 0 & $0 \%$ & 1 & $0.4 \%$ & .24 & 23 & $2.1 \%$ & 20 & $2.4 \%$ & 3 & $1.1 \%$ & .32 & 72 & $6.6 \%$ & 53 & $6.4 \%$ & 19 & $7.3 \%$ & .6 \\
\hline$\geq \mathrm{T} 3$ & 0 & $0 \%$ & 0 & $0 \%$ & 0 & $0 \%$ & 1 & 13 & $1.9 \%$ & 10 & $1.9 \%$ & 3 & $1.9 \%$ & 1 & 45 & $6.5 \%$ & 33 & $6.3 \%$ & 12 & $7.4 \%$ & .61 \\
\hline Total & 6 & $0.1 \%$ & 3 & $0.1 \%$ & 3 & $0.2 \%$ & .15 & 269 & $4.1 \%$ & 220 & $4.5 \%$ & 49 & $3.2 \%$ & .02 & 456 & $7.0 \%$ & 348 & $7.1 \%$ & 108 & $6.9 \%$ & .87 \\
\hline
\end{tabular}

Abbreviation: CTLS, CT lung screening.

Table 6. CTLS Metrics by Screening Round: CDR, PPV, and SPV

\begin{tabular}{|c|c|c|c|c|c|c|c|c|c|c|c|c|c|c|c|}
\hline \multirow{3}{*}{$\begin{array}{l}\text { Screening } \\
\text { Round } \\
\text { T0 }\end{array}$} & \multicolumn{7}{|c|}{ Lung Cancers Detected (CDR) } & \multicolumn{4}{|c|}{ PPV } & \multicolumn{4}{|c|}{ SPV } \\
\hline & \multicolumn{2}{|c|}{ Overall } & \multicolumn{2}{|c|}{ Group 1} & \multicolumn{2}{|c|}{ Group 2} & \multirow{2}{*}{$\frac{P \text { Value }}{.61}$} & \multirow{2}{*}{$\begin{array}{c}\text { Overall } \\
16.6 \%\end{array}$} & \multirow{2}{*}{$\begin{array}{c}\text { Group } 1 \\
17.2 \%\end{array}$} & \multirow{2}{*}{$\begin{array}{c}\text { Group } 2 \\
14.3 \%\end{array}$} & \multirow{2}{*}{$\begin{array}{c}P \text { Value } \\
.54\end{array}$} & \multirow{2}{*}{$\begin{array}{c}\text { Overall } \\
37.0 \%\end{array}$} & \multirow{2}{*}{$\begin{array}{c}\text { Group } 1 \\
38.7 \%\end{array}$} & \multirow{2}{*}{$\begin{array}{c}\text { Group } 2 \\
29.6 \%\end{array}$} & \multirow{2}{*}{$\frac{P \text { Value }}{.38}$} \\
\hline & 66 & $2.3 \%$ & 52 & $2.3 \%$ & 14 & $2.0 \%$ & & & & & & & & & \\
\hline T1 & 28 & $1.6 \%$ & 23 & $1.7 \%$ & 5 & $1.2 \%$ & .41 & $21.8 \%$ & $23.6 \%$ & $20.0 \%$ & .68 & $43.9 \%$ & $46.5 \%$ & $42.9 \%$ & .81 \\
\hline $\mathrm{T} 2$ & 11 & $1.0 \%$ & 4 & $0.5 \%$ & 7 & $2.7 \%$ & .005 & $15.4 \%$ & $8.2 \%$ & $37.5 \%$ & .01 & $29.4 \%$ & $17.4 \%$ & $54.5 \%$ & .04 \\
\hline$\geq \mathrm{T} 3$ & 8 & $1.2 \%$ & 6 & $1.1 \%$ & 2 & $1.2 \%$ & 1 & $19.5 \%$ & $19.4 \%$ & $20.0 \%$ & 1 & $32.0 \%$ & $31.6 \%$ & $33.3 \%$ & 1 \\
\hline Total & 113 & $1.7 \%$ & 85 & $1.7 \%$ & 28 & $1.8 \%$ & .84 & $17.7 \%$ & $17.6 \%$ & $18.8 \%$ & .76 & $37.0 \%$ & $37.3 \%$ & $37.9 \%$ & .93 \\
\hline
\end{tabular}

Abbreviations: CDR, cancer detection rate; CTLS, CT lung screening; PPV, positive predictive value; SPV, suspicious predictive value. 


\section{References}

1. Wood DE, Eapen GA, Ettinger DS, et al. NCCN Clinical Practice Guidelines in Oncology: Lung Cancer Screening. Version 1.2012. Accessed April 2, 2012. To view the most recent version of these guidelines, visit NCCN.org.

2. Moyer VA; for the U.S. Preventive Services Task Force. Screening for lung cancer: U.S. Preventive Services Task Force recommendation statement. Ann Intern Med 2014;160:330-338.

3. Decision Memo for Screening for Screening for Lung Cancer with Low Dose Computed Tomography (LDCT) (CAG-00439N). CMS.gov Web site. Available at: https://www.cms.gov/medicare-coverage-database/ details/nca-decision-memo.aspx?NCAId=274. Accessed April 2nd, 2016.

4. National Lung Screening Trial Research Team, Aberle DR, Adams AM, et al. Reduced lung-cancer mortality with low-dose computed tomographic screening. N Engl J Med 2011;365:395-409.

5. Detterbeck FC, Mazzone PJ, Naidich DP, Bach PB. Screening for lung cancer. Diagnosis and management of lung cancer, 3rd ed: American College of Chest Physicians evidence-based clinical practice guidelines. Chest 2013;143:e78S-92S.

6. Wood DE, Kazerooni EA, Baum SL, et al. NCCN Clinical Practice Guidelines in Oncology: Lung Cancer Screening. Version 3.2018. Accessed February 20, 2018. To view the most recent version of these guidelines, visit NCCN.org.
7. McKee BJ, McKee AB, Flacke S, et al. Initial experience with a free, highvolume, low-dose CT lung cancer screening program. J Am Coll Radiol 2013;10:586-592.

8. Lung CT Screening Reporting \& Data System. American College of Radiology Web site. Available at: http://www.acr.org/Quality-Safety/ Resources/LungRADS. Accessed October 7, 2014.

9. Jaklitsch MT, Jacobson FL, Austin JH, et al. The American Association for Thoracic Surgery guidelines for lung cancer screening using low-dose computed tomography scans for lung cancer survivors and other high-risk groups. J Thorac Cardiovasc Surg 2012;144:33-38.

10. Kovalchik SA, Tammemagi M, Berg CD, et al. Targeting of low-dose CT screening according to the risk of lung-cancer death. N Engl J Med 2013;369:245-254.

11. Pinsky PF, Kramer BS. Lung cancer risk and demographic characteristics of current 20-29 pack-year smokers: implications for screening. J Natl Cancer Inst 2015;107:djv226.

12. Pinsky PF, Zhu CS, Kramer BS. Lung cancer risk by years since quitting in 30+ pack year smokers. J Med Screen 2015;22:151-157.

13. McKee BJ, McKee AB, Kitts AB, et al. Low-dose computed tomography screening for lung cancer in a clinical setting: essential elements of a screening program. J Thorac Imaging 2015;30:115-129.

14. Black WC, Gareen IF, Soneji SS, et al. Cost-effectiveness of CT screening in the National Lung Screening Trial. N Engl J Med 2014;371:1793-1802.

15. Ma J, Ward EM, Smith R, Jemal A. Annual number of lung cancer deaths potentially avertable by screening in the United States. Cancer 2013;119:1381-1385.

\section{See JNCCN.org for supplemental online content.}

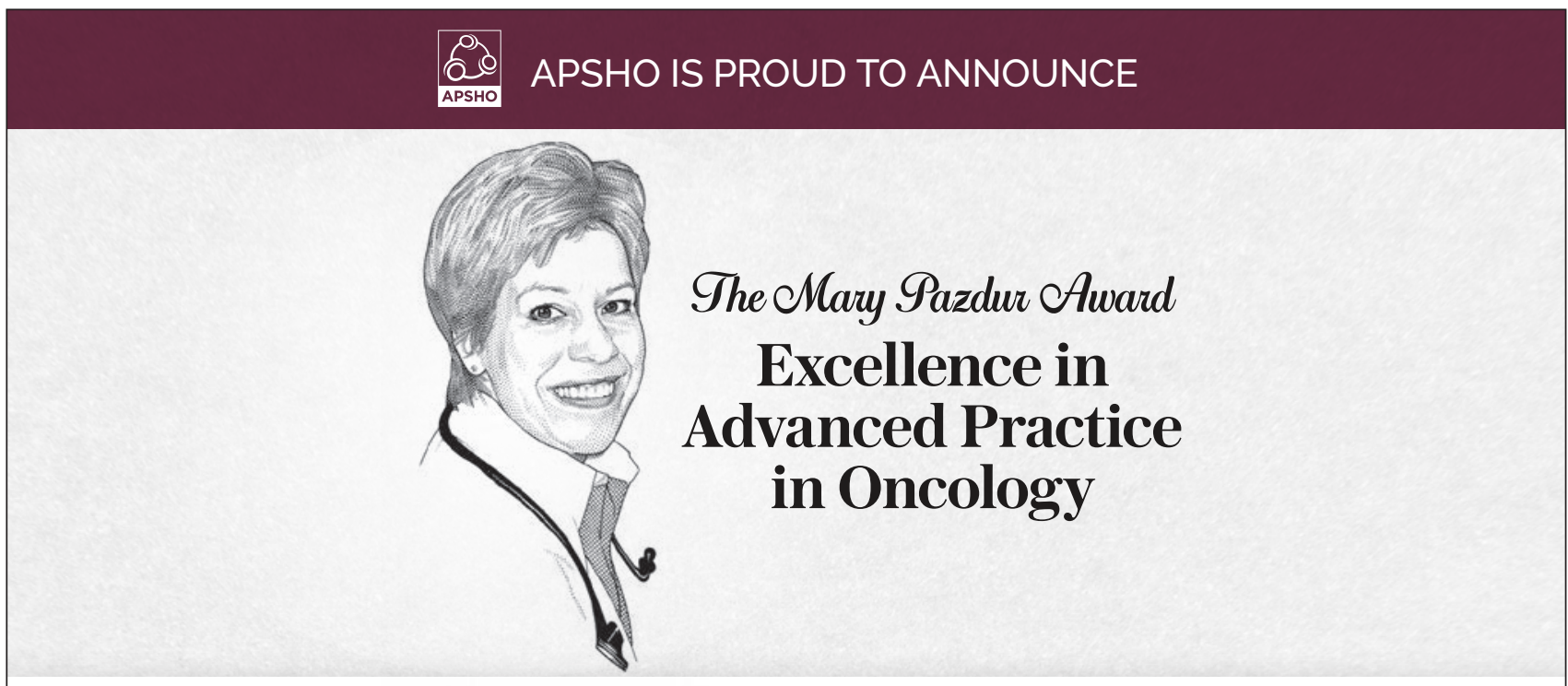

\section{Do you know an exceptional advanced practitioner?}

\section{HURRY! ALL NOMINATIONS MUST BE RECEIVED BY MAY 31, 2018}

The winner of the award will receive a $\$ 5,000$ grant, a trip to JADPRO Live 2018 , and recognition both at the conference and in an issue of the Journal of the Advanced Practitioner in Oncology (JADPRO).

Nominate a colleague today at marypazduraward.com 